\title{
Preservation of graft function in low-risk living kidney transplant recipients treated with a combination of sirolimus and cyclosporine
}

\footnotetext{
P.G.P. Machado ${ }^{1}$,

C.R. Felipe ${ }^{1}$, S.I. Park ${ }^{1}$,

R. Garcia ${ }^{1}$, S. Moreira ${ }^{1}$,

D. Casarini ${ }^{1}$, M. Franco ${ }^{2}$,

F. Alfieri ${ }^{3}$, H. Tedesco-Silva Jr. ${ }^{1}$

and J.O. Medina-Pestana ${ }^{1}$
}

\author{
'Divisão de Nefrologia, Hospital do Rim e Hipertensão, and \\ ${ }^{2}$ Departamento de Patologia, Universidade Federal de São Paulo, \\ São Paulo, SP, Brasil \\ ${ }^{3}$ Laboratórios Wyeth-Ayerst do Brasil, São Paulo, SP, Brasil
}

\section{Correspondence \\ H. Tedesco Silva Jr. \\ Divisão de Nefrologia \\ Hospital do Rim e Hipertensão \\ UNIFESP \\ Rua Borges Lagoa, 960, 119 andar \\ 04038-002 São Paulo, SP \\ Brasil \\ Fax: 55-11-5087-8008 \\ E-mail: heliotedesco@hrim.com.br \\ Presented in part at the 18th International Congress of the Transplantation Society, Transplant 2001, Chicago, IL, USA, May 11-16, 2001. \\ Research supported by Wyeth-Ayerst Laboratories, São Paulo, SP, Brazil.}

Publication supported by FAPESP.

Received September 12, 2003 Accepted April 20, 2004

\begin{abstract}
The use of sirolimus (SRL) in combination with full doses of cyclosporin A (CsA) results in reduced one-year kidney allograft function, which is associated with shorter long-term allograft survival. We determined the effect of reduced CsA exposure on graft function in patients receiving SRL and prednisone. Ninety recipients of living kidney transplants receiving SRL ( $2 \mathrm{mg} / \mathrm{day}$, po) were compared to 35 recipients receiving azathioprine (AZA, $2 \mathrm{mg} \mathrm{kg}^{-1}$ $\left.\mathrm{day}^{-1}, p o\right)$. All patients also received CsA $\left(8-10 \mathrm{mg} \mathrm{kg}^{-1} \mathrm{day}^{-1}, p o\right)$ and prednisone $\left(0.5 \mathrm{mg} \mathrm{kg}^{-1} \mathrm{day}^{-1}\right)$. Efficacy end-point was a composite of biopsy-confirmed acute rejection, graft loss, or death at one year. Graft function was measured by creatinine, creatinine clearance, and graft function deterioration between 3 and 12 months $(\Delta 1 / \mathrm{Cr})$. CsA concentrations in patients receiving SRL were $26 \%$ lower. No differences in one-year composite efficacy end-point were observed comparing SRL and AZA groups (18 vs 20\%) or in the incidence of biopsy-proven acute rejection (14.4 and 14.3\%). There were no differences in mean \pm SD creatinine $(1.65 \pm 0.46 v s$ $1.60 \pm 0.43 \mathrm{mg} / \mathrm{dl}, \mathrm{P}=0.48)$ or calculated creatinine clearances $(61 \pm$ 15 vs $62 \pm 13 \mathrm{ml} / \mathrm{min}, \mathrm{P}=0.58)$ at one year. Mean $\pm \mathrm{SD} \Delta 1 / \mathrm{Cr}(-11 \pm$ $17 v s-14 \pm 15 \%, \mathrm{P}=0.7)$ or the percentage of patients with $>20 \%$ (26 vs $31 \%, \mathrm{P}=0.6)$ or $>30 \% \Delta 1 / \mathrm{Cr}(19$ vs $17 \%, \mathrm{P}=1)$ did not differ between the two groups. The use of 2-mg fixed oral doses of SRL and reduced CsA exposure was effective in preventing acute rejection and preserving allograft function.
\end{abstract}

\section{Introduction}

Two phase III, large, prospective, randomized, multicenter, double-blind international clinical trials have shown that sirolimus
Key words

- Sirolimus

- Cyclosporine

- Graft function

- Immunosuppression

- Kidney transplantation
( 2 and $5 \mathrm{mg}$ ) in combination with full doses of cyclosporin (CsA) and corticosteroids reduces the incidence, severity, and need of antibody therapy to treat acute rejection episodes compared to azathioprine (AZA) (1) or 
placebo (2). However, patients receiving sirolimus showed impaired allograft function 6 and 12 months after transplantation, measured by either serum creatinine or calculated creatinine clearances. Since sirolimus is a critical-dose drug and has no nephrotoxic effects of its own, the effect on graft function has been attributed to pharmacokinetic and pharmacodynamic interactions between sirolimus and CsA, increasing the susceptibility of allografts to CsA-associated nephrotoxic effects (3).

Impaired graft function at one year has been associated with inferior long-term allograft survival (4). Hence, strategies to improve graft function using sirolimus/CsA drug combinations are required (5). One approach is to withdraw CsA 3 months after transplantation, which has resulted in lower blood pressure and improved calculated glomerular filtration rate at one year compared to patients who continue to receive the sirolimus/CsA combination (63 vs $57 \mathrm{ml} /$ min, $\mathrm{P}<0.0001$ ) (6). Although higher doses of sirolimus were used after CsA withdrawal, a higher incidence of rejection was observed (9.8 vs 4.2\%, $\mathrm{P}=0.035)$ along with a higher incidence of thrombocytopenia and hypokalemia. Abnormal liver function tests were also observed, leading to an overall higher rate of drug discontinuation (27 vs $18 \%, \mathrm{P}=0.028)$.

Since sirolimus and CsA show synergistic effects both in vitro and in vivo (7), another strategy to maintain the efficacy of the $\mathrm{CsA}$ /sirolimus combination while preserving renal function is to use reduced CsA doses and exposures. However, the time and magnitude of dose reduction have not been systematically investigated $(8,9)$. We analyzed here the effectiveness of the use of initial full doses of CsA, with reduction of CsA exposure one month after transplantation, in patients receiving 2-mg fixed daily doses of sirolimus and prednisone, compared with standard triple therapy. Also, we correlated blood concentrations of $\mathrm{CsA}$ and sirolimus with graft function at one year.

\section{Subjects and Methods}

\section{Population}

Between June 13, 1999 and October 8, 2000, 70 recipients of one-haplotype living related kidney allografts were enrolled in a single center, open label, randomized trial comparing sirolimus $(\mathrm{N}=35)$ versus AZA $(\mathrm{N}=35)$ as part of a $\mathrm{CsA}$ microemulsion and prednisone immunosuppressive regimen. In a concomitant multicenter, international, single arm trial, 55 recipients of fully mismatched living related or unrelated allografts also received a combination of sirolimus, CsA microemulsion and prednisone. Patients with end-stage renal disease, 13 years of age or older, weighing $40 \mathrm{~kg}$ or more, all first recipients of a kidney graft and with a negative $\mathrm{T}$ cell crossmatch, were eligible for inclusion in both trials. Women of childbearing potential were required to have a negative pregnancy test before administration of the study medication and to practice medically approved birth control throughout the study and for 3 months following discontinuation of sirolimus. The protocol also required the patients to have total white blood cell count $\geq 4.0 \times 10^{9} / 1$, platelet count $\geq 100.0 \times 10^{9} / 1$, fasting cholesterol $\leq 350 \mathrm{mg} / \mathrm{dl}(\leq 9.1 \mathrm{mmol} /$ 1) and/or fasting triglycerides $\leq 500 \mathrm{mg} / \mathrm{dl}$ $(\leq 5.65 \mathrm{mmol} / \mathrm{l})$ during a pretransplant screening evaluation. High-risk patients deemed to receive antibody induction (retransplants, reactive antibody panel $\geq 50 \%$, pediatric recipients under 12 years of age) were excluded from the study. Patients were also excluded if they had evidence of systemic infection, a history of clinically significant cardiac abnormalities or malignancy within 10 years of enrollment into the study and had received treatment with an investigation agent within 4 weeks of sirolimus administration. Patients were not allowed to participate in the trial if they were receiving any immunosup- 
pressive agent before transplantation or any known cytochrome P450 inducers/inhibitors, including terfenadine, cisapride, astemizole, or pimozide. Patients with abnormal chest radiography findings, known hypersensitivity to macrolides or those who required antibody induction therapy were also excluded. Prophylaxis for Pneumocystis carinii pneumonia with trimethoprim-sulfamethoxazole was mandatory for all patients during the 12-month treatment period. Prophylaxis for cytomegalovirus infection was also mandatory in cytomegalovirus-negative patients who had received a kidney from a cytomegalovirus-positive donor. These patients were required to take acyclovir for 3 months after transplantation. The local medical Ethics Committee approved all the protocols and the studies were performed in accordance with the Declaration of Helsinki and U.S. Food and Drug Administration guidelines for good clinical practice. All patients signed a written informed consent after they had been informed about the nature and details of the studies.

\section{Immunosuppressive treatment and monitoring}

Prior to graft revascularization all patients received $1 \mathrm{~g}$ methylprednisolone. Within 24 $\mathrm{h}$ after transplant surgery, the patients received an initial CsA dose of 8 to $10 \mathrm{mg} /$ day twice daily, $0.5 \mathrm{mg} \mathrm{kg}^{-1}$ day $^{-1}$ prednisone up to a maximum of $30 \mathrm{mg} /$ day, and AZA ( $2 \mathrm{mg}$ $\mathrm{kg}^{-1} \mathrm{day}^{-1}$ ) or sirolimus (a 6-mg loading dose followed by a 2-mg fixed daily dose of sirolimus, $1 \mathrm{mg} / \mathrm{ml}$; Wyeth-Ayerst Research, Radnor, PA, USA), administered $4 \mathrm{~h}$ after the morning CsA dose. Blood CsA and sirolimus concentrations were measured at weeks 1 , $2,4,8,12,24,36$, and 52. Doses of CsA were adjusted to keep trough whole blood CsA concentrations between 200 and 400 $\mathrm{ng} / \mathrm{ml}$ during the first 4 weeks, between 150 and $300 \mathrm{ng} / \mathrm{ml}$ from week 5 to 12 , and between 100 to $200 \mathrm{ng} / \mathrm{ml}$ thereafter. After the fourth post-transplant week, patients receiving sirolimus had their CsA doses adjusted to keep blood concentrations within the lower range of the therapeutic window, in contrast to patients receiving AZA who had their CsA doses adjusted to the upper level.

\section{Efficacy analysis}

Since all patients followed the same concentration-controlled CsA-based immunosuppressive regimen, we pooled together all patients who received sirolimus $(\mathrm{N}=90)$ and compared them with those who received AZA $(\mathrm{N}=35)$. All patients were followed for 12 months and an intention-to-treat analysis was used to assess efficacy failure, defined as the composite of biopsy-proven acute rejection, graft loss or death at 12 months. All episodes of graft dysfunction were investigated and a core biopsy was performed whenever indicated. A local pathologist graded the histological diagnoses according to the 1997 BANFF criteria (10). Biopsy-proven acute rejection episodes were treated initially with methylprednisolone, 0.5 to $1 \mathrm{~g}$ for 3 to 5 days. Biopsy-proven steroid-resistant acute rejections were treated with OKT3, a first dose of $5 \mathrm{mg}$ followed by $2.5 \mathrm{-mg}$ daily doses to keep CD3-positive cells below $10 / \mathrm{mm}^{3}$. Time to and histological grade of first biopsy-confirmed acute rejection were also analyzed. Graft loss was defined as physical loss due to nephrectomy, functional loss requiring maintenance dialysis for more than 8 weeks, or death with a functioning graft.

\section{Graft function}

To understand the impact of the continuous use of sirolimus on graft function of patients receiving CsA, only patients receiving either sirolimus and CsA or AZA and CsA up to 12 months post-transplant (per-protocol population) were used for the analysis of 
graft function. First we compared serum creatinine values at months $1,2,3,4,6,9$, and 12 and calculated creatinine clearances at 3, 6 and 12 months, using the CockcroftGault formula (11). Second, we investigated the magnitude of loss of function between 3 and 12 months post-transplant using the $\Delta 1 /$ $\mathrm{Cr}$, a strong time-dependent predictor of graft failure (12). Baseline graft function was assessed during the first 3 months after transplantation using the mean of the 3 lowest creatinine values. In each group, graft function deterioration at 12 months was determined by comparing mean percent $\Delta 1 /$ $\mathrm{Cr}$ and the percentage of patients showing higher than $-20 \%$ or $-30 \% \Delta 1 / \mathrm{Cr}$ at 12 months.

\section{Bioanalytical methods}

Whole blood CsA concentrations were determined with the AxSYM CsA fluorescence polarization immunoassay kit (Abbott Laboratories, Abbott Park, IL, USA), according to manufacturer directions. Performance was assessed on the basis of a 3-point quality control concentration range of low (70 $\mathrm{ng} / \mathrm{ml})$, intermediate $(300 \mathrm{ng} / \mathrm{ml})$, and high $(600 \mathrm{ng} / \mathrm{ml})$ concentrations. Whole blood sirolimus concentrations were measured using an HPLC method adapted from Maleki et al. (13). Briefly, $75 \mu l$ of internal standard solution (desmethoxysirolimus) was added to $500 \mu \mathrm{l}$ of whole blood calibrators and clinical samples. Sirolimus was extracted using $1 \mathrm{ml}$ $5 \% \mathrm{ZnSO}_{4}$ and $1 \mathrm{ml}$ acetone. Two hundred microliters $100 \mathrm{mM} \mathrm{NaOH}$ and $2 \mathrm{ml} \mathrm{1-}$ chlorobutane were added to the superntants, vortexed and centrifuged. The upper organic layer $(2 \mathrm{ml})$ was pipetted off and evaporated to dryness. Sample extracts were reconstituted with $150 \mu \mathrm{l}$ of an acetonitrile/water (70:30) mixture and $500 \mu \mathrm{l}$ hexane was added, vortexed and centrifuged. The hexane layer was pipetted off and $50 \mu \mathrm{l}$ was injected into a reverse-phase C18 column $\left(50^{\circ} \mathrm{C}\right.$, flow rate of $\left.1.0 \mathrm{ml} / \mathrm{min}\right)$. Ultraviolet detection was performed at $278 \mathrm{~nm}$ and quantification of sirolimus was based on a peak area ratio. Analytical recovery of 93.8 to $109.0 \%$ was observed throughout the linear range of the assay $(2.5-150.0 \mathrm{ng} / \mathrm{ml})$. The lower limit of quantification was set at $2.5 \mathrm{ng} / \mathrm{ml}$ (coefficient of variation $=9.6 \%$ ). The intra-assay precision ranged from 2 to $15 \%$, and the interassay precision ranged from 5.5 to $9.3 \%$.

\section{Statistical analysis}

The sample size was determined using the Cochran and Cox formula (14). For the purpose of this study we estimated that the acute rejection rates without and with the use of sirolimus at 3 months would be 32 and $4 \%$, respectively, according to data already available from the global study (2). With a significance level of 0.05 in a two-sided test, and a power of 0.80 , the required number of patients in each group was 25 , for a total of 50 patients. All patients were followed for 12 months. To determine whether reduced exposure to CsA was effective an intention to treat analysis was used to compare the incidence of biopsy-proven acute rejection, graft loss or death observed in 90 patients receiving sirolimus and in 35 patients receiving AZA at 12 months. To determine whether reduced exposure to CsA preserved graft function, only patients who received the sirolimus, CsA, and prednisone combination during the entire 12-month follow-up period were included and compared with patients who received AZA, CsA, and prednisone. Continuous variables were analyzed by the unpaired Student $t$-test or by analysis of variance. Categorical variables were analyzed by the chi-square or Fisher exact test depending on the number of observations. Whisker and box plots and the chi-square test were used to show and compare blood sirolimus concentrations, creatinine and creatinine clearances. Multiple regression analyses were used to correlate CsA and 
sirolimus concentration with graft function at one year. Statistical analysis was done using the SPSS 7.5 software (SPSS Inc.). Differences were considered significant at $\mathrm{P}$ $<0.05$.

\section{Results}

\section{Demographics}

The demographic characteristics of this patient population, as shown in Table 1, are representative of our general adult transplant population. Mean age was $38.1 \pm 10.8$ years, mean weight $64.9 \pm 9.6 \mathrm{~kg}$, and mean body mass index $23.8 \pm 2.8 \mathrm{~kg} / \mathrm{m}^{2}$. Sixty-eight percent of the patients were males and $64 \%$ were white. The most frequent causes of end-stage renal disease were chronic glomerulonephritis (22\%), hypertension (22\%) and diabetes $(8 \%)$ and these patients had been on hemodialysis for a mean time of 21.0 \pm 16.6 months. Mean human leukocyte antigen (HLA) mismatch was $3.3 \pm 1.0$ and the vast majority of the patients $(96 \%)$ had reactive antibody panel of less than $5 \%$. All patients were hepatitis $\mathrm{B}$ and $\mathrm{C}$ negative and 90\% were cytomegalovirus positive. Except for older age and mean HLA mismatch, no other significant differences were observed in baseline demographic characteristics between patients receiving sirolimus or AZA (Table 1).

\section{Immunosuppression and monitoring}

Mean CsA dose (week 4 to week 52, Figure 1A) and blood concentrations (week 12 to week 52, Figure 1B) were significantly lower among patients receiving sirolimus. However, there were no significant differences in dose-normalized CsA concentrations between groups (data not shown). Mean trough whole blood sirolimus concentrations were $5.2 \pm 3.1$ at day $7,7.5 \pm 3.6$ at week $4,7.9 \pm 4.1$ at week $8,8.2 \pm 4.2$ at week $12,7.8 \pm 4.5$ at week 24 , and $8.4 \pm 6.0$ at week 52 (Figure 2). Mean sirolimus concentrations significantly increased from week 1 to week $16(5.2 \pm 3.1$ vs $9.8 \pm 5.7, \mathrm{P}<$ $0.0001)$. Mean individual sirolimus concentrations showed a 10 -fold variation from 2.5 to $23.5 \mathrm{ng} / \mathrm{ml}$. Prednisone taper was faster in patients receiving sirolimus (week 4: $24.2 \pm$ 8.7 vs $27.1 \pm 5.36, \mathrm{P}=0.062$; week $8: 14.5$

Table 1. Demographic characteristics of the transplant population.

\begin{tabular}{|c|c|c|c|c|}
\hline & $\begin{array}{c}\text { Total } \\
(\mathrm{N}=125)\end{array}$ & $\begin{array}{l}\text { Sirolimus } \\
(N=90)\end{array}$ & $\begin{array}{l}\text { Azathioprine } \\
(N=35)\end{array}$ & $P$ value \\
\hline Age (years) & $\begin{array}{l}38.1 \pm 10.8 \\
(15.0-63.0)\end{array}$ & $\begin{array}{c}40.0 \pm 10.4 \\
(19.0-63.0)\end{array}$ & $\begin{array}{c}33.2 \pm 10.5 \\
(15.0-58.0)\end{array}$ & 0.001 \\
\hline $\begin{array}{l}\text { Gender (male/ } \\
\text { female) }\end{array}$ & $85(68) / 40$ (32) & $61(68) / 29(32)$ & $24(69) / 11$ (31) & 1.000 \\
\hline Weight (kg) & $\begin{array}{l}64.9 \pm 9.6 \\
(32.1-89.0)\end{array}$ & $\begin{array}{l}65.1 \pm 9.9 \\
(32.1-89.0)\end{array}$ & $\begin{array}{l}64.4 \pm 9.0 \\
(46.8-87.7)\end{array}$ & 0.739 \\
\hline $\begin{array}{l}\text { Body mass index } \\
\qquad\left(\mathrm{kg} / \mathrm{m}^{2}\right)\end{array}$ & $\begin{array}{l}23.8 \pm 2.8 \\
(12.2-31.5)\end{array}$ & $\begin{array}{c}23.9 \pm 3.2 \\
(12.2-31.5)\end{array}$ & $\begin{array}{c}23.6 \pm 1.6 \\
(20.8-25.7)\end{array}$ & 0.680 \\
\hline \multicolumn{5}{|l|}{ Ethnicity } \\
\hline White & $80(64)$ & $58(64)$ & $22(63)$ & 0.874 \\
\hline Black & $20(16)$ & $13(14)$ & 7 (20) & \\
\hline Mulate & $21(17)$ & $16(18)$ & $5(14)$ & \\
\hline Others & $4(3)$ & $3(4)$ & $1(3)$ & \\
\hline \multicolumn{5}{|l|}{ Cause of ESRD } \\
\hline Hypertension & 22 (18) & $18(20)$ & $4(11)$ & 0.068 \\
\hline $\begin{array}{l}\text { Chronic } \\
\text { glomerulonephritis }\end{array}$ & $28(22)$ & $14(16)$ & $14(40)$ & \\
\hline Diabetes mellitus & $10(8)$ & $9(10)$ & $1(3)$ & \\
\hline Nephrosclerosis & $6(5)$ & $4(4)$ & $2(6)$ & \\
\hline Others & 59 (17) & $45(50)$ & $14(40)$ & \\
\hline \multicolumn{5}{|l|}{ Viral status } \\
\hline $\begin{array}{l}\text { Anti-HCV positive } \\
\text { (lgG) }\end{array}$ & $0(0) / 125(100)$ & $0(0) / 90(100)$ & $0(0) / 35(100)$ & 1.000 \\
\hline HbsAg positive & $0(0) / 125(100)$ & $0(0) / 90 \quad(100)$ & $0(0) / 35(100)$ & 1.000 \\
\hline CMV positive (lgG) & $112(90) / 13(10)$ & 82 (91)/8 (9) & $30(86) / 5(14)$ & 0.514 \\
\hline $\begin{array}{l}\text { Time on dialysis } \\
\text { (months) }\end{array}$ & $\begin{array}{c}21.0 \pm 16.6 \\
(2.0-75.0)\end{array}$ & $\begin{array}{c}22.4 \pm 17.2 \\
(2.0-75.0)\end{array}$ & $\begin{array}{c}20.4 \pm 14.1 \\
(3.0-58.0)\end{array}$ & 0.223 \\
\hline HLA mismatchs & $\begin{array}{l}3.3 \pm 1.0 \\
(2.0-6.0)\end{array}$ & $\begin{array}{c}3.4 \pm 1.2 \\
(2.0-6.0)\end{array}$ & $\begin{array}{c}2.8 \pm 0.5 \\
(2.0-4.0)\end{array}$ & 0.003 \\
\hline $\begin{array}{l}\text { Reactive antibody } \\
\text { panel }(<5 \% / \geq 5 \%)\end{array}$ & $120(96) / 5$ & $88(98) / 2(2)$ & $32(91) / 3(9)$ & 1.000 \\
\hline Donor age (years) & $42.8 \pm 9.9$ & $42.8 \pm 10.0$ & $42.9 \pm 9.9$ & 0.970 \\
\hline $\begin{array}{l}\text { Delayed graft } \\
\text { function (\%) }\end{array}$ & 6.4 & 5.6 & 8.6 & 0.685 \\
\hline
\end{tabular}

Data are reported as mean $\pm \mathrm{SD}$ (range). $\mathrm{CMV}=$ cytomegalovirus; $\mathrm{ESRD}=$ end-stage renal disease; $\mathrm{HCV}=$ hepatitis $\mathrm{C}$ virus; $\mathrm{HLA}=$ human leukocyte antigen.

${ }^{*} \mathrm{P}<0.05$ for sirolimus vs azathioprine (unpaired Student $t$-test for continuous and chi-square test for categorical variables). 
\pm 5.3 vs $19.93 \pm 3.71, \mathrm{P}=0.001$; week 12 : $10.9 \pm 2.7$ vs $14.50 \pm 4.36, \mathrm{P}=0.006)$. Mean AZA doses were $126.4 \pm 30.3$ and $116.1 \pm$ $30.7 \mathrm{mg}$ at week 1 and 52, respectively.

\section{Efficacy}

Twelve-month composite efficacy failure (biopsy-confirmed acute rejection, graft loss or death) was $18 \%$ in the sirolimus group and
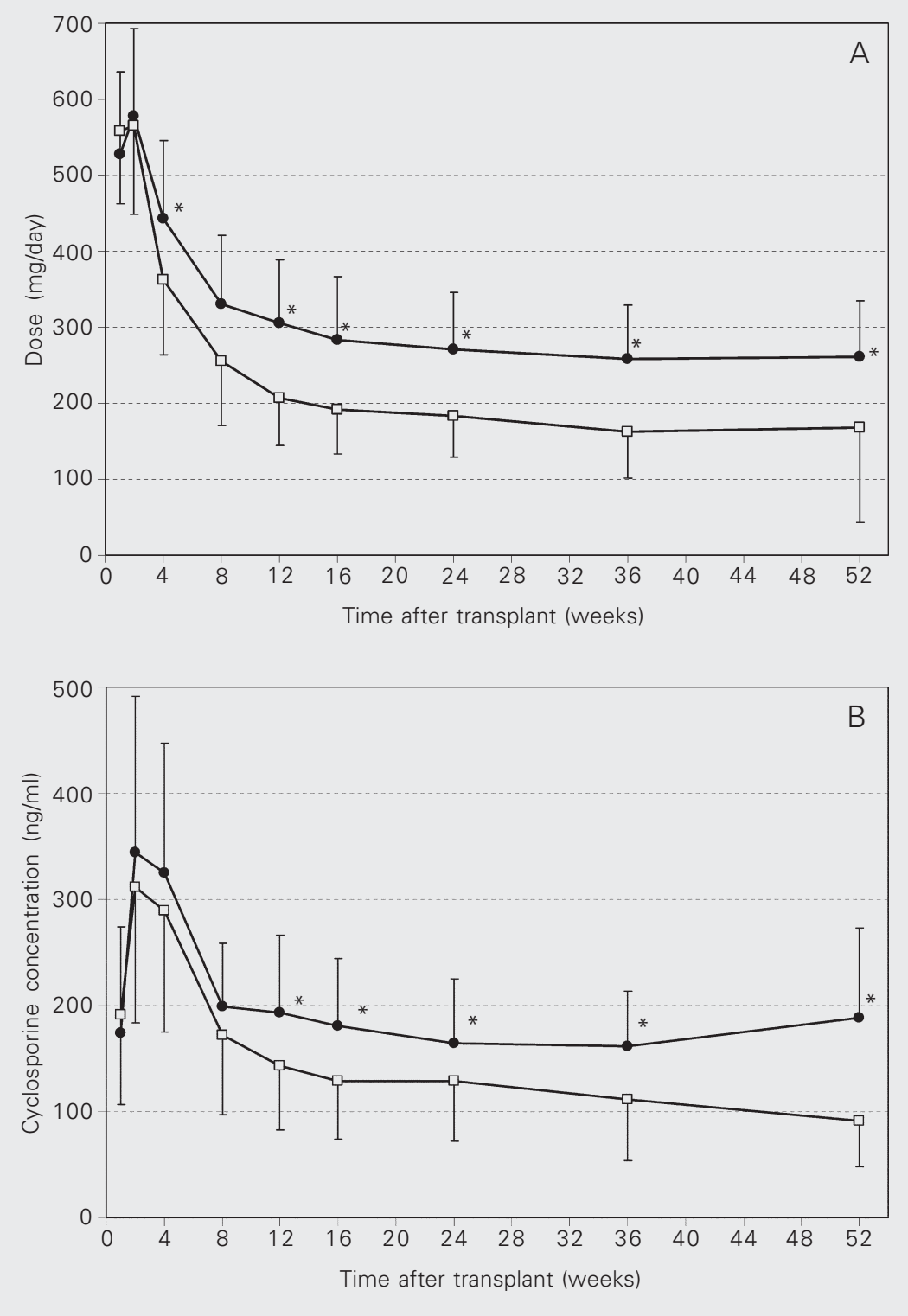

Figure 1. Mean cyclosporine daily doses (A) and trough whole blood concentrations (B) in patients receiving sirolimus (squares) or azathioprine (circles). ${ }^{*} \mathrm{P}<0.05$ comparing mean values at each time of transplant (unpaired Student $t$-test).
$20 \%$ in the AZA group. The incidence of biopsy-proven acute rejection was $14.4 \%$ $(13 / 90)$ and $14.3 \%(5 / 35)$. Sirolimus treatment delayed the time to first biopsy-proven acute rejection $(119.8 \pm 108.4$ vs $6.2 \pm 2.6$ days, $\mathrm{P}=0.05)$. There were 3 graft losses, 2 in the sirolimus group (recurrence of segmental and focal glomerulosclerosis, persistent urinary fistula) and 1 in the AZA group (recurrence of segmental and focal glomerulosclerosis). There were 4 deaths, 3 in the sirolimus group (sepsis, cerebrovascular hemorrhage, sudden death) and 1 in the AZA group (sudden death) (Table 2).

\section{Safety}

There were 17 (14\%) treatment discontinuations, 14 in the sirolimus group (16\%) and 3 in the AZA group (9\%). In the sirolimus group, 4 patients were switched from CsA to tacrolimus after an acute rejection episode. Due to adverse events, CsA was discontinued in one patient with hemolytic uremic syndrome, and sirolimus was discontinued in 9 patients ( 3 cases of hyperlipidemia, 2 of acute tubular necrosis, 2 of anemia, 1 case of graft dysfunction, and 1 case of sepsis). In the AZA group, CsA was discontinued in one patient with early and rapidly progressive recurrence of segmental and focal glomerulosclerosis. AZA was discontinued in 2 patients due to hepatotoxicity and severe cytomegalovirus infection (Table 2).

\section{Graft function}

At 12 months, protocol population consisted of 105 patients, 74 in the sirolimus group and 31 in the AZA group, which was considered for the analysis of graft function. Twenty patients were excluded, including 17 drug discontinuations and 3 deaths. There were no significant differences in baseline demographic characteristics between the intention-to-treat and per-protocol population. Comparing patients receiving sirolimus 
or AZA, at 3 months there were no differences in mean creatinine values $(1.46 \pm 0.35$ vs $1.44 \pm 0.34 \mathrm{mg} / \mathrm{dl})$ or mean creatinine clearances $(65 \pm 16$ vs $65 \pm 14 \mathrm{ml} / \mathrm{min})$. At 6 months, patients receiving AZA showed lower mean serum creatinine $(1.62 \pm 0.43 \mathrm{vs}$ $1.45 \pm 0.34 \mathrm{mg} / \mathrm{dl}, \mathrm{P}=0.045)$ and higher mean calculated creatinine clearance $(62 \pm$ 17 vs $65 \pm 17 \mathrm{ml} / \mathrm{min}, \mathrm{P}=0.02$ ) but at 12 months there were no differences in mean creatinine $(1.65 \pm 0.46$ vs $1.60 \pm 0.43 \mathrm{mg} / \mathrm{dl})$ or calculated creatinine clearance $(61 \pm 15 \mathrm{vs}$ $62 \pm 13 \mathrm{ml} / \mathrm{min}, \mathrm{P}=0.58$ ) (Figures 3 and 4 ). At 12 months, mean $\Delta 1 / \mathrm{Cr}$ did not differ between the AZA and sirolimus groups (-11 $\pm 17 v s-14 \pm 15 \%, \mathrm{P}=0.7)$. The percentage of patients with $\Delta 1 / \mathrm{Cr}$ higher than $-20 \%$ (26 (8/31) vs $31 \%$ (23/75), $\mathrm{P}=0.6)$ or higher than $-30 \%$ (19 (6/31) vs 17\% (13/75), $\mathrm{P}=1)$ also did not differ. Multiple linear regression analysis showed no significant correlations between blood CsA concentrations at 1 month, at 3 months, mean individual sirolimus concentrations and graft function measured by creatinine, calculated creatinine clearance, and $\Delta 1 / \mathrm{Cr}$. There were no correlations between the mean individual sirolimus concentrations divided into quartiles $(\leq 6 \mathrm{ng} / \mathrm{ml}$, 6.1-7.7 ng/ml, 7.8-9.5, and $>9.5 \mathrm{ng} / \mathrm{ml}$ ) and graft function at one year.

\section{Discussion}

Acute rejection and graft function at one year are good predictors of late kidney graft loss $(4,15)$. Therefore, the benefit of the combination of sirolimus with full doses of CsA in reducing the incidence of acute rejection might be counterbalanced by the impaired graft function seen at one year in patients receiving this drug combination $(1,2)$. Here we demonstrate that reduction of CsA dose, beginning 4 weeks after transplanta-
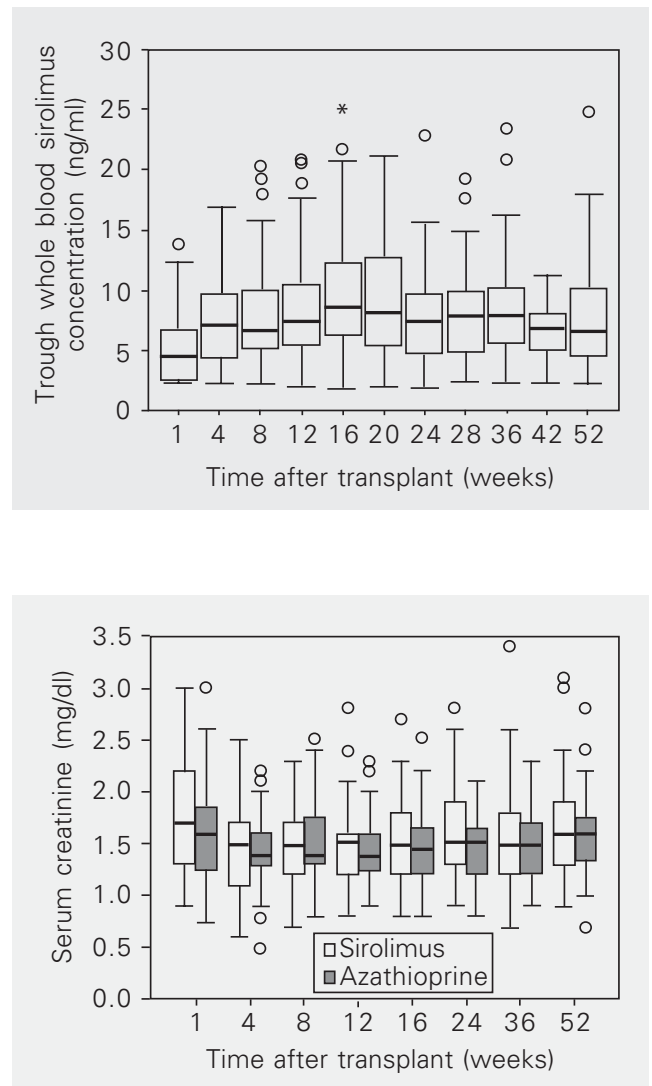

Figure 2. Trough whole blood sirolimus concentrations during the first year after transplantation. Middle horizontal thick bar is the median; the top and bottom square lines indicate the 75th and 25th percentiles; the error bars denote the limits of the 90th and 10th percentiles; open circles are outliers. ${ }^{*} \mathrm{P}=$ 0.012 (ANOVA, week 1 through week 16).

Table 2. Efficacy and safety analysis one year after kidney transplantation.

\begin{tabular}{lccc}
\hline Parameters - N (\%) & Total $(\mathrm{N}=125)$ & Sirolimus $(\mathrm{N}=90)$ & Azathioprine (N = 35) \\
\hline Composite end-point & $23(18.4)$ & $16(17.8)$ & $7(20.0)$ \\
Biopsy-confirmed acute rejection & $18(14.4)$ & $13(14.4)$ & $5(14.3)$ \\
BANFF (IA/IB/IIA/IIB/III) & $8 / 4 / 6 / 0 / 0$ & $6 / 3 / 4 / 0 / 0$ & $2 / 0 / 2 / 0 / 1$ \\
Graft loss & $3(2.4)$ & $2(2.2)$ & $1(2.9)$ \\
Death & $4(3.2)$ & $3(3.3)$ & $1(2.9)$ \\
Study drug discontinuation & $17(13.6)$ & $14(15.5)$ & $3(8.6)$ \\
$\quad$ Lack of efficacy & $4(3.2)$ & $4(4.4)$ & $3(0.0)$ \\
Adverse event & $13(10.4)$ & $10(11.1)$ & $3(8.6)$ \\
\hline
\end{tabular}

There was no significant difference between sirolimus vs AZA for any of the parameters (chi-square test).

Figure 3. Serum creatinine concentrations in patients receiving sirolimus or azathioprine during the first year after transplantation. The middle horizontal thick bar is the median; the top and bottom square lines indicates the 75th and 25th percentiles; the error bars denote the limits of the 90th and 10th percentiles; open circles are outliers. $\mathrm{P}>0.05$ comparing sirolimus and azathioprine values on the occasion of each visit (unpaired Student $t$-test). 
tion, was effective in maintaining a low incidence of acute rejection rate while improving one-year graft function, which was similar to that seen in the control group of patients receiving AZA, in contrast to the findings of the phase III clinical trials in which patients receiving the CsA and sirolimus combination showed impaired graft function compared to patients receiving CsA and AZA (1).

Efficacy as well as safety analysis showed that the immunosuppressive strategy resulted in comparable incidences of acute rejection rates when full CsA doses were used in multicenter trials $(1,2)$, and that tolerability was very good with only $11 \%$ of patients discontinuing CsA or sirolimus due to an adverse event. It is important to point out that the entire population consisted of recipients of living donor allografts, minimizing the influence of brain death, donor injury, ischemia, preservation and reperfusion injuries, and delayed graft function on one-year graft function. Moreover, the very low incidence of biopsy-confirmed acute rejection rate in the AZA group was unexpected, perhaps related to the small sample size since our historical and current acute rejection rates are about $30 \%$, reducing the impact of acute rejection on one-year graft function in this group of patients.

The doses of CsA were reduced by $18 \%$ at week 4 , reaching $35 \%$ at week 52 . This resulted in an $11 \%$ and $51 \%$ reduction in CsA

Figure 4. Calculated creatinine clearances by patients receiving sirolimus or azathioprine. The middle horizontal thick bar is the median; the top and bottom square lines indicates the 75th and 25th percentiles; the error bars denote the limits of the 90th and 10th percentiles. ${ }^{*} \mathrm{P}<$ 0.05 comparing sirolimus and azathioprine at each time (unpaired Student $t$-test).

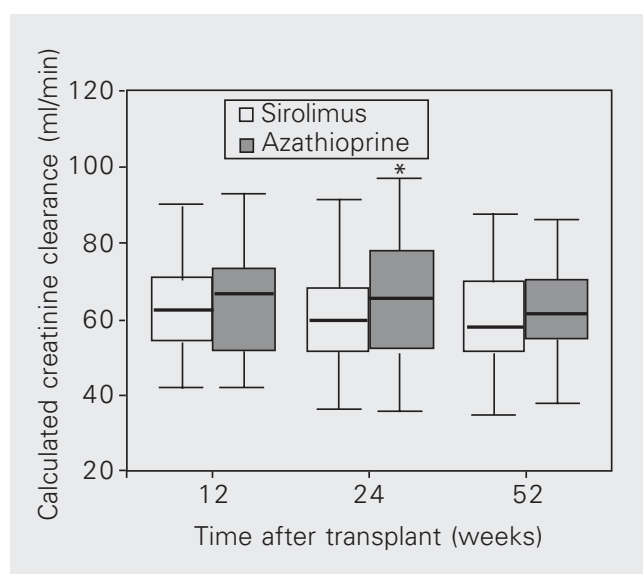

concentrations at weeks 4 and 52, respectively. Dose-normalized CsA concentrations did not differ between sirolimus and AZA patients, suggesting that the doses used in this study did not produce significant pharmacokinetic interaction between sirolimus and CsA in the blood compartment. Blood sirolimus concentrations increased progressively from week 4 to week 16 (Figure 2). During this period CsA concentrations were reduced by about $25 \%$ compared to AZA patients, and significant differences were observed in graft function at 24 weeks (Figures 3 and 4). A further $25 \%$ reduction in CsA concentrations from week 24 to 52 resulted in an improvement of graft function at one year. Mean individual sirolimus concentrations or CsA concentrations at 1 and 3 months showed no linear relationship with graft function. Even when mean individual sirolimus concentrations were divided into quartiles, no relationship with graft function was observed. Since we were using 2-mg fixed doses of sirolimus and were not aware of blood sirolimus concentrations, we were unable to reduce the dose of CsA even further, which might have resulted in additional improvement in graft function at one year.

Recently, the use of therapeutic sirolimus monitoring has allowed safer, earlier, and higher reduction in CsA exposure, providing the opportunity to design protocols that may result in better kidney graft function (16). In one study 309 patients showing therapeutic sirolimus concentrations (5-15 or 10-20 ng/ $\mathrm{ml})$ were randomized to full $(150-300 \mathrm{ng} / \mathrm{ml})$ or reduced (50-125 ng/ml) CsA exposures 3 months after transplantation, respectively. There were no significant differences in biopsy-confirmed acute rejection (10.5 vs $12.6 \%)$ or graft function at 6 months (1.69 vs $1.58 \mathrm{mg} / \mathrm{dl}$ ) (17). In another study 400 patients were randomized to receive full or reduced CsA exposures. At 6 months, patients in both groups showed mean sirolimus concentrations of $9.1 \mathrm{ng} / \mathrm{ml}$ and mean CsA 
concentrations of 165.3 and $104.9 \mathrm{ng} / \mathrm{ml}$, respectively. Again, there were no significant differences in biopsy-confirmed acute rejection (5.6 vs 10\%) or graft function at 6 months (2.03 vs $1.78 \mathrm{mg} / \mathrm{dl})$ (18).

An interesting finding was that maintenance of lower CsA exposures did not increase the proportion of patients showing higher than -20 or $-30 \% \Delta 1 / \mathrm{Cr}$, suggesting that there was no increase in the rate of graft function deterioration from 3 to 12 months compared to patients receiving AZA. Taken together, these results suggest that the administration of initial full doses of cyclosporine for 1 to 3 months, even when followed by subsequent dose reduction or withdrawal, may produce significant and probably irreversible kidney graft damage. These assumptions are supported by the results of trials in which patients receiving sirolimusbased immunosuppressive regimens showed better graft function at one year, with mean creatinine values of $1.31 \mathrm{mg} / \mathrm{dl}(115.8 \mu \mathrm{M})$ using the combination of sirolimus and azathioprine (19), $1.45 \mathrm{mg} / \mathrm{dl}(128.3 \mu \mathrm{M})$ using the combination of sirolimus and mycophenolate mofetil (20), and $1.32 \mathrm{mg} / \mathrm{dl}$ using the combination of basiliximab, sirolimus and mycophenolate mofetil (21). Also, progressively lower acute rejection rates, 41, 27.5 and $6.4 \%$, were seen in this three latter trials, respectively. The analysis of all these studies suggests that complete avoidance of CsA and low rejection rates seem to be associated with better graft function at one year and perhaps with increased long-term graft survival. On the other hand, while during treatment with the sirolimus/CsA combination withdrawal of steroids appears to be safe (22), there are no data about the safety of this strategy in patients using sirolimusbased immunosuppressive therapies. Currently, in this cohort of patients, $42 \%$ of patients in the sirolimus group were not treated with steroids for a mean follow-up time of $201 \pm 265$ (93-648) days. If reduced acute rejection rates and good graft function, produced by new, although more expensive, immunosuppressive drugs, in fact translate into prolonged long-term graft survival compared to the old cyclosporine, azathioprine, and prednisone combination, then we may say that this new regimens will also be costeffective. Nevertheless, large and prospective clinical trials will be needed to assess the long-term efficacy and safety of calcineurin inhibitor avoidance and steroid withdrawal immunosuppressive regimens (23).

We conclude that in low risk recipients of living kidney transplants the use of 2-mg fixed doses of sirolimus and prednisone, with early reduction in CsA exposure was effective, safe and preserved graft function at one year compared to patients receiving AZA. Improvements in the use of sirolimus/ CsA combinations using therapeutic drug monitoring may allow even earlier and further reduction CsA exposure, a potential strategy to improve long-term patient and graft outcomes.

\section{References}

1. Kahan BD (2000). Efficacy of sirolimus compared with azathioprine for reduction of acute renal allograft rejection: a randomised multicentre study. The Rapamune US Study Group. Lancet, 356: 194202.

2. MacDonald AS (2001). A worldwide, phase III, randomized, controlled, safety and efficacy study of a sirolimus/cyclosporine regimen for prevention of acute rejection in recipients of primary mismatched renal allografts. Transplantation, 71: 271-280.

3. Podder H, Stepkowski SM, Napoli KL, Clark J, Verani RR, Chou TC \& Kahan BD (2001). Pharmacokinetic interactions augment toxici- ties of sirolimus/cyclosporine combinations. Journal of the American Society of Nephrology, 12: 1059-1071.

4. Hariharan S, McBride MA, Cherikh WS, Tolleris CB, Bresnahan BA \& Johnson CP (2002). Post-transplant renal function in the first year predicts long-term kidney transplant survival. Kidney International, 62: $311-318$

5. Kreis H (2001). New strategies to reduce nephrotoxicity. Transplantation, 72 (Suppl): S99-S104.

6. Johnson RW, Kreis H, Oberbauer R, Brattstrom C, Claesson K \& Eris J (2001). Sirolimus allows early cyclosporine withdrawal in renal 
transplantation resulting in improved renal function and lower blood pressure. Transplantation, 72: 777-786.

7. Kahan BD \& Kramer WG (2001). Median effect analysis of efficacy versus adverse effects of immunosuppressants. Clinical Pharmacology and Therapeutics, 70: 74-81.

8. Morales JM, Andres A, Rengel M \& Rodicio JL (2001). Influence of cyclosporin, tacrolimus and rapamycin on renal function and arterial hypertension after renal transplantation. Nephrolology, Dialysis, Transplantation, 16 (Suppl 1): 121-124.

9. Pescovitz MD \& Govani M (2001). Sirolimus and mycophenolate mofetil for calcineurin-free immunosuppression in renal transplant recipients. American Journal of Kidney Diseases, 38 (Suppl 2): S16-S21.

10. Racusen LC, Solez K, Colvin RB et al. (1999). The BANFF 97 working classification of renal allograft pathology. Kidney International, 55: 713-723.

11. Cockcroft DW \& Gault MH (1976). Prediction of creatinine clearance from serum creatinine. Nephron, 16: 31-41.

12. Kasiske BL, Andany MA \& Danielson B (2002). A thirty percent chronic decline in inverse serum creatinine is an excellent predictor of late renal allograft failure. American Journal of Kidney Diseases, 39: 762-768.

13. Maleki S, Graves S, Becker S, Horwatt R, Hicks D, Stroshane RM \& Kincaid $H$ (2000). Therapeutic monitoring of sirolimus in human whole-blood samples by high-performance liquid chromatography. Clinical Therapeutics, 22 (Suppl B): B25-B37.

14. Cochran WG \& Cox GM (1950). Experimental Design. John Wiley and Sons, Inc., New York, 71-72.

15. Chan L, Gaston R \& Hariharan S (2001). Evolution of immunosuppression and continued importance of acute rejection in renal transplantation. American Journal of Kidney Diseases, 38 (Suppl): S2-S9.

16. Kahan BD, Napoli KL, Kelly PA, Podbielski J, Hussein I, Urbauer DL,
Katz SH \& Van Buren CT (2000). Therapeutic drug monitoring of sirolimus: correlations with efficacy and toxicity. Clinical Transplantation, 14: 97-109.

17. Cohen DJ \& Vincenti FA (2002). Comparative, open-label study to evaluate graft function in de novo renal allograft recipients treated with reduced-dose or standard-dose cyclosporine in combination with sirolimus and corticosteroids. American Journal of Transplantation, 2: S237 (Abstract).

18. Muhlbacher F \& Paczek L (2002). An open-label study to evaluate the efficacy \& safety of cyclosporine reduction in de novo renal allograft recipients receiving sirolimus: a dose comparative study. American Journal of Transplantation, 2: S238 (Abstract).

19. Groth CG, Backman L, Morales JM et al. (1999). Sirolimus (rapamycin)-based therapy in human renal transplantation: similar efficacy and different toxicity compared with cyclosporine. Sirolimus European Renal Transplant Study Group. Transplantation, 67: 10361042.

20. Kreis H, Cisterne JM, Land W et al. (2000). Sirolimus in association with mycophenolate mofetil induction for the prevention of acute graft rejection in renal allograft recipients. Transplantation, 69: 1252-1260

21. Flechner SM, Goldfarb D, Modlin C, Feng J, Krishnamurthi V, Mastroianni B, Savas K, Cook DJ \& Novick AC (2002). Kidney transplantation without calcineurin inhibitor drugs: a prospective, randomized trial of sirolimus versus cyclosporine. Transplantation, 74: 1070-1076.

22. Mahalati K \& Kahan BD (2001). A pilot study of steroid withdrawal from kidney transplant recipients on sirolimus-cyclosporine as combination therapy. Transplantation Proceedings, 33: 3232-3233.

23. Pascual $M$, Theruvath $T$, Kawai $T$, Tolkoff-Rubin $N$ \& Cosimi $A B$ (2002). Strategies to improve long-term outcomes after renal transplantation. New England Journal of Medicine, 346: 580-590. 